\title{
BMJ Open Identifying women's preferences for treatment of urinary tract infection: a discrete choice experiment
}

\author{
Henk van der Worp (D), Daan Brandenbarg, Pieter A Boek, Jort H W Braams, \\ Leon J F Brink, Joost Keupers, Marco H Blanker
}

To cite: van der Worp H, Brandenbarg D, Boek PA, et al. Identifying women's preferences for treatment of urinary tract infection: a discrete choice experiment. BMJ Open 2021;11:e049916. doi:10.1136/ bmjopen-2021-049916

- Prepublication history and additional supplemental material for this paper are available online. To view these files, please visit the journal online (http://dx.doi.org/10.1136/ bmjopen-2021-049916)

Received 04 February 2021 Accepted 28 October 2021

Check for updates

(C) Author(s) (or their employer(s)) 2021. Re-use permitted under CC BY-NC. No commercial re-use. See rights and permissions. Published by BMJ.

Department of General Practice and Elderly Care Medicine, University Medical Center Groningen, University of Groningen, Groningen, The Netherlands

Correspondence to Dr Henk van der Worp; h.van.der.worp@umcg.nl

\section{ABSTRACT}

Objective To identify the preferences of women regarding management of urinary tract infections (UTIS).

Design A discrete choice experiment of the preferences

for certain treatment attributes was conducted by survey. Attributes included treatment duration, time to complaint resolution, complication risk, side effect risk and contribution to antimicrobial resistance.

Setting General population in the Netherlands, recruited via social media.

Participants Women aged 18 years or older.

Primary and secondary outcome measures The primary outcome was the relative importance of the attributes for treatment choice, using a conditional logit model. The secondary outcome was the heterogeneity in these preferences.

Results The discrete choice experiment was completed by 833 women. Most attributes were important to decisions for UTI treatment. Women were willing to accept management with, for example, a higher chance of complications or longer time to resolution, if it could help avoid antimicrobial resistance. However, there was heterogeneity in the preferences. Women who had one previous UTI had a stronger preference for faster symptom resolution compared with those who had no previous UTI. Younger women also preferred faster symptom resolution. Finally, women with a low or middle education level gave less importance to preventing antimicrobial resistance than women with a high education level.

Conclusions The current study indicated that a considerable part of women valued alternatives to antimicrobial treatment and were prepared to tolerate management that was less optimal in certain respects to avoid antimicrobial treatment.

\section{INTRODUCTION}

Urinary tract infections (UTIs) in women are a common complaint in Dutch general practice, having an incidence of 124 per 1000 patient-years. ${ }^{1}$ According to the Dutch guideline for general practitioners (GPs), management of UTI can employ either antimicrobial treatment or a wait-and-see approach in combination with analgesia. ${ }^{2}$ This guideline advocates the wait-and-see approach as an option on the basis that antimicrobial resistance may be prevented at the cost of a small

\section{Strengths and limitations of this study}

- Using a discrete choice experiment can generate useful information about the characteristics underlying treatment preferences.

- Survey distribution through social media precluded insight into who did and did not complete the survey.

- Using social media may also have led to a less representative sample that was over-represented by respondents with a high level of education.

increase in the risk of pyelonephritis and a longer time to symptom resolution. Antibiotic resistance should be avoided as it may lead to longer illness and increased mortality, increased costs of treatment, and not being able to perform medical procedures that need antibiotics for infection prevention. ${ }^{3}$ However, despite the ongoing problem of antimicrobial resistance and despite the existence of a viable alternative approach, antimicrobial drug prescribing for UTIs increased in the Netherlands from 88 to 153 per 1000 person-years between 1996 and 2014. ${ }^{4}$ More recent data suggest that this trend changed and prescriptions decreased a little. ${ }^{5}$ Although prescription of antimicrobial drugs in the Netherlands is low compared with most other European countries where antimicrobial resistance may be even a larger issue, the issue of antimicrobial resistance is of vital importance in the Netherlands as well. ${ }^{6}$

Given that itis appropriate to treat with either medication or the wait-and-see approach, patient preference should play an important role in choosing one over the other. Research has shown that patient preferences are taken into account when prescribing antimicrobial drugs when they are considered to be one of the options in the guideline. ${ }^{7}$ Also, when shared decision making was applied, fewer antimicrobial drugs were prescribed ${ }^{8}$ Unfortunately, however, little is known about the underlying characteristics of these treatment 
preferences for UTI among women. Specifically it would be interesting to know whether women would tolerate a less optimal treatment in terms of efficacy and harms if use of antimicrobial drugs can be avoided.

In the present study, our primary aim was to identify the preferences of women for certain UTI treatment characteristics. Our secondary aim was to assess the heterogeneity in these preferences.

\section{METHODS}

\section{Study design and participants}

We performed a discrete choice experiment (DCE) to gain insight into the preferences of women regarding UTI management. Women aged 18 years or older were invited via social media, especially Facebook, LinkedIn and Twitter, from 1 May to 30 May 2020, to give their opinion on the treatment of UTI. All authors used their personal social media accounts for this. The authors also used snowball sampling by asking participants to distribute the link within their social network. Women were asked to complete the study survey irrespective of their history of UTI and received no reimbursement for participating. Participants gave informed consent before participation.

\section{The discrete choice experiment}

DCEs are used to identify preferences based on decisions made by respondents when confronted with hypothetical scenarios. ${ }^{910}$ In a DCE, it is assumed that the preferences of respondents are based on the underlying characteristics of the goods or service in question.

Where treatment is considered the service, characteristics may cover various treatment attributes, such as complication risk or treatment duration. Each attribute is then given several levels. For example, if we consider treatment duration as the attribute, levels could be 1 day, 3 days and 5 days, reflecting relevant treatment periods for antimicrobial therapy in UTI. Respondents are presented with two or more scenarios for which the levels of the attributes vary and they must choose their preferred scenario. In this way, they are forced to make a trade-off between scenarios based on the relative importance of different attributes and levels. It is assumed that an individual, when faced with a choice between two or more alternatives, will choose the alternative they deem more favourable.

A list of attributes and levels was created for use in this study based on expert GP opinion and patient opinion. For patient opinion, semistructured interviews about UTIs, treatment and treatment choice were conducted with five women who had recently experienced a UTI. A literature review was performed to realistic levels for the attributes. The following attributes (levels are detailed in parentheses) were included: duration of treatment (1, 3 or 5 days), time to complaint resolution (1, 4 or 7 days), complication risk $(0 \%$ or $5 \%)$, side effect risk $(0 \%, 2.5 \%$
Which option do you prefer for treatment of a urinary tract infection?

\begin{tabular}{rcc}
\hline & Option A & Option B \\
\hline Treatment duration & 5 days & 1 days \\
Resolution of complaints & 1 days & 1 days \\
Chance of complications & $0 \%$ & $5 \%$ \\
Chance of side-effects & $0 \%$ & $2.5 \%$ \\
Contribute to antim icrobial resistance & Yes & No \\
\hline
\end{tabular}

\section{[1. Option A}

0. Option B

Figure 1 Example of a choice task. The task presents two options, A and B, with attributes detailed on the left. Respondents are asked to select the option that they prefer.

or 10\%) and contribution to antimicrobial resistance (yes or no). The experiment was piloted by the research team.

A so-called full factorial design was not feasible because the number of attributes and levels in our study $(3 \times 3 \times 2 \times 3 \times 2=108$ scenarios $)$ would produce too many different comparison scenarios $(108 \times[\{108-1\} / 2]=5778)$. Therefore, we opted to use a non-full factorial design, ${ }^{11}$ generating a D-efficient fractional experimental design using the Idefix package (V.0.4.3) in R V.4.0.0 (R Core Team). ${ }^{12}$ D-efficiency is the most commonly used metric for efficient design construction. ${ }^{11}$ The experiment comprised 16 two-choice tasks (online supplemental file 1 ), an example of which is shown in figure 1 . The order of the choice tasks was randomised, and the survey was implemented in Qualtrics (Qualtrics, Provo, Utah).

Besides the choice tasks, the survey included questions about age, education level and history of UTI (online supplemental file 2). Finally, the explicit opinion of respondents concerning antimicrobial resistance was assessed based on their responses to two propositions: (1) I am aware of the risks of antimicrobial resistance, for me and others, that can follow after using antimicrobial drugs; and (2) It is important to consider the risk of antimicrobial resistance in my treatment choices.

\section{Statistical analysis}

Analyses were performed using STATA V.16. Descriptive data were calculated for the total group and for subgroups based on history of UTI. For the primary aim, data were analysed using a conditional logit model ${ }^{13}$ and the results were used to assess the trade-off between antimicrobial resistance and the other attributes. For the secondary aim, data were analysed using a latent-class conditional logit model to assess preference heterogeneity. The Akaike information criterion (AIC) was used to select the number of classes, which was done by visual inspection of a plot of the AIC against the number of classes. Identified classes were compared with respect to preferences and characteristics, and the characteristics were assessed with a class assignment model to give the probability of participants with certain characteristics belonging to a certain class. The last class was taken as the reference in this analysis. Education level was dichotomised into low/medium and high due to the small number of subjects with low education level. 
Table 1 Characteristics of the total group and of subgroups by history of UTI

\begin{tabular}{lllll}
\hline & \multicolumn{1}{c}{ History of UTI } & & & \\
\cline { 2 - 5 } & Total & $\mathbf{0}$ & $\mathbf{1}$ & \multicolumn{1}{c}{$\mathbf{1}$} \\
\hline $\mathrm{n}$ & 833 & 148 & 136 & 549 \\
Age (years), mean \pm SD & $43.7 \pm 14.9$ & $41.6 \pm 15.5$ & $42.4 \pm 15.2$ & $44.6 \pm 14.7$ \\
$\begin{array}{l}\text { Education level (\%) } \\
\quad \text { Low }\end{array}$ & 3.7 & & & \\
$\quad$ Middle & 15.1 & 2.7 & 3.7 & 4.0 \\
$\quad$ High & 81.1 & 16.9 & 14.7 & 14.8 \\
\hline Antimicrobial resistance (\% yes) & & 80.4 & 81.6 & 81.2 \\
$\quad$ Aware of risks & 98.9 & & & 98.9 \\
$\quad$ Important in treatment choice & 97.8 & 98.7 & 99.3 & 97.3 \\
\hline
\end{tabular}

UTI, urinary tract infection.

\section{Patient and public involvement statement}

We engaged patients in the design of the experiment by using semistructured interviews to gather information about the preferences and experiences of women who had recently had a UTI. This information was subsequently used to select the attributes and levels for the DCE.

\section{RESULTS}

The DCE was completed by 833 women with a mean age of $43.7 \pm 14.9$ years; of these, most reported at least one previous UTI ( $\mathrm{n}=549)$ (table 1), most had a high level of education $(81.1 \%)$, and most indicated that they recognised the risks of antimicrobial resistance and would consider this when weighing treatment options.

The conditional logit analysis showed that most attributes were statistically significant, indicating that they played a role in decision making for UTI treatment (table 2). The signs of the coefficients indicated that

Table 2 Conditional logit model: treatment preferences for UTI by attribute level

\begin{tabular}{|c|c|c|}
\hline Attribute level & Coefficient & $95 \% \mathrm{Cl}$ \\
\hline \multicolumn{3}{|c|}{ Treatment duration (reference $=1$ day) } \\
\hline 3 days & -0.05 & -0.12 to 0.02 \\
\hline 5 days & -0.26 & -0.32 to -0.20 \\
\hline \multicolumn{3}{|c|}{ Time to resolution of complaints (reference $=1$ day) } \\
\hline 4 days & -0.68 & -0.79 to -0.58 \\
\hline 7 days & -2.03 & -2.20 to -1.87 \\
\hline Risk of complications (\%) & -0.19 & -0.20 to -0.17 \\
\hline Risk of side effects (\%) & -0.16 & -0.17 to -0.14 \\
\hline $\begin{array}{l}\text { Increases resistance }{ }^{*} \text { (vs } \\
\text { not) }\end{array}$ & -1.33 & -1.45 to -1.21 \\
\hline
\end{tabular}

Bold indicates significance at the $5 \%$ level.

*Antimicrobial resistance.

UTI, urinary tract infection. respondents preferred shorter treatment duration, shorter time to resolution, fewer complications and side effects, and an approach that did not increase antimicrobial resistance. Comparing the size of the coefficients for the different attributes indicated that participants were willing to tolerate treatment lasting 5 days longer (coefficient $=-0.26$ ) and 4 days longer to resolution (coefficient $=-0.68$ ), as well as more complications (coefficient $=-0.19$ ) and side effects (coefficient=-0.16), if this avoided contributing to antimicrobial resistance (coefficient $=-1.33$ ).

Three latent classes were identified, with $17 \%, 38 \%$ and $45 \%$ of the participants being included in classes 1, 2 and 3 , respectively (table 3 ). Class 3 was treated as the reference for comparison, differing from the other classes in placing greater value on preventing antimicrobial resistance and less value on time to symptom resolution. However, in general, classes did not differ much in the importance given to treatment duration or to the risks of complications and side effects.

Class 1 differed from the other classes in giving less importance to preventing antimicrobial resistance, as illustrated by the positive coefficient in this class (1.16; 95\% CI 0.96 to 1.36). Participants were more likely to belong to this class than to the reference class if they had low/middle education level. Class 2 differed from the other classes in placing greater value on faster symptom resolution, as illustrated by the considerably larger coefficient for 7 days on this attribute $(-6.09$; $95 \%$ CI -6.79 to -5.40$)$. Younger women or those who had suffered one previous UTI had a higher probability of belonging to this class than to the reference class. Class 3 differed from the other classes in that they placed greater value on preventing antimicrobial resistance and less value on time to resolution compared with both other classes.

\section{DISCUSSION}

Women participating in this DCE via an online survey were willing to tolerate longer treatment duration, longer 
Table 3 Differences in relative importance of UTI treatment preferences between identified latent classes for each attribute and level

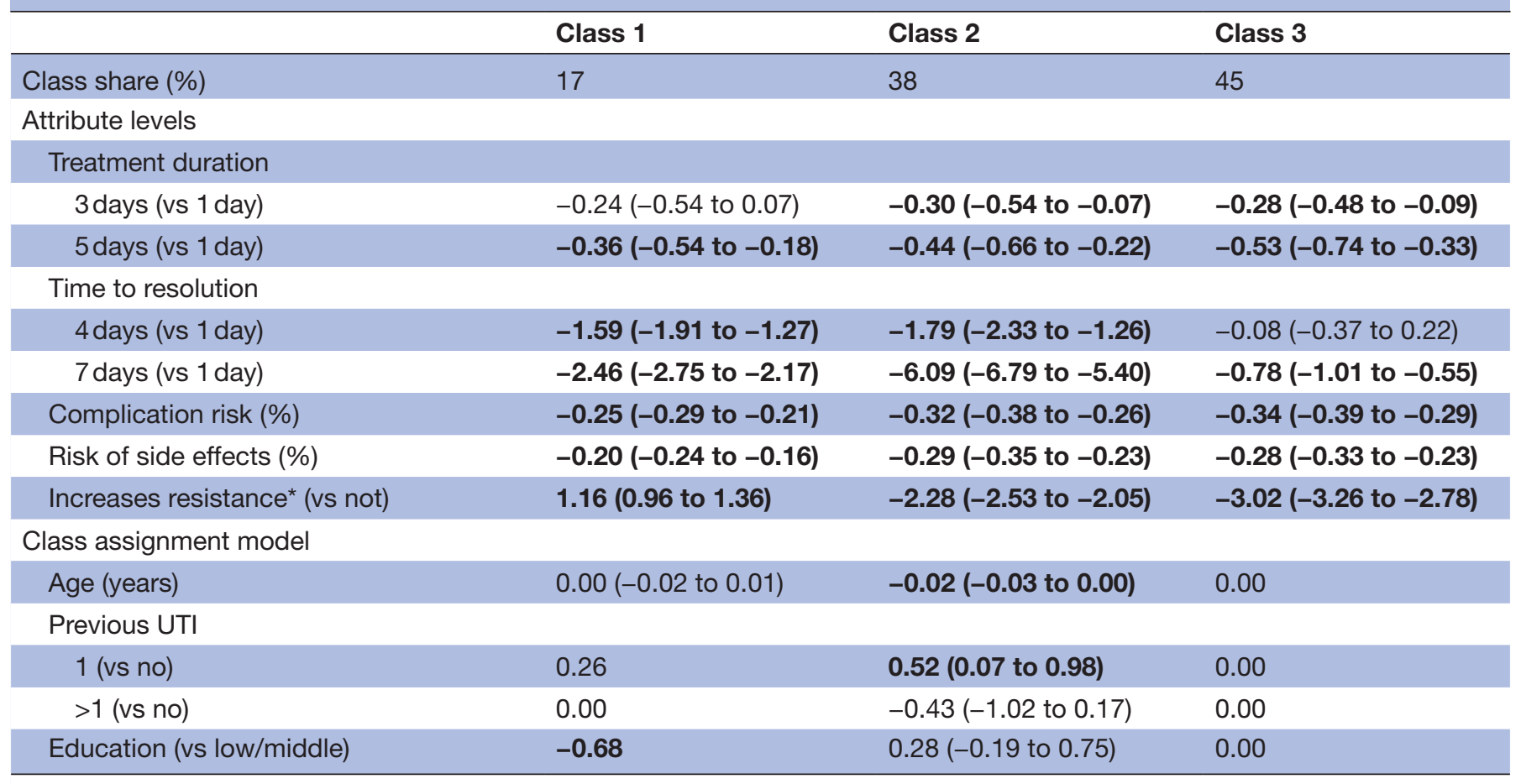

Results of the latent-class conditional logit model.

Bold indicates significance at the $5 \%$ level.

Data are shown as coefficients $(95 \% \mathrm{Cl})$.

${ }^{*}$ Antimicrobial resistance.

UTI, urinary tract infection.

time to symptom resolution, and increased side effect and complication risks to avoid antimicrobial resistance when being treated for UTI. The preference to avoid antimicrobial resistance was strongest among women with a higher level of education, whereas those who were younger or had only experienced one previous UTI placed greater value on quicker resolution of complaints.

The present study benefited from having a large sample size and from using the DCE method, which combined generated useful information about the characteristics underlying treatment preferences. However, our findings were limited by our decision to use social media to distribute the survey, resulting in a lack of data on who did and did not complete the survey because it was not distributed to a preselected sample. The study sample may also not have been representative of the general population because distribution through social media will have resulted in a cohort that approximated the researchers' own social networks. For example, over $80 \%$ of our respondents had a high education level, which reflects only $30 \%-35 \%$ of the general population. ${ }^{14}$ This may have implications for the generalisability of the results. Despite these factors, the considerable sample size allowed for subgroups to be identified that had distinctive characteristics and showed differences in preferences related to level of education. Also, the mean age of the women in our study was comparable with a study that assessed all UTI consultations in Norway over a 10 -year period, suggesting that the impact of the recruitment method on age was limited. ${ }^{15}$

We restricted the information collection to shorten the time to complete the experiment and to attract more participants. As such, demographic information of our study sample was sparse, which could be considered a limitation as well. There may however be other important demographic factors that can help identify demographic groups with certain preferences, such as healthcare utilisation or work circumstances.

We did not perform a sample size calculation but used a practical approach that is often used to maximise the sample size given the budget and time. ${ }^{16}$ A rule of thumb observed in simulation studies is that between 150 and 300 subjects are needed. ${ }^{11}$ There has been limited research on women's preferences for treatment to date. In a qualitative study of data from a randomised controlled trial on UTI therapy, 20 women were interviewed and reported that they wanted to avoid antimicrobial treatment and were open to treatment alternatives, including a delayed prescription for antimicrobial treatment. ${ }^{17}$ One mentioned that they preferred the other treatment specifically to avoid the side effects of antimicrobial treatment. However, antimicrobial treatment was preferred by two who believed that this would lead to a more rapid symptom relief, consistent with reports from other studies 
on this topic. In another qualitative study, about half of the women reported that they would agree to delaying an antimicrobial drug prescription, although fear of missing serious illness was the main barrier. ${ }^{18}$ Following this thread, two studies in the Netherlands assessed the proportion of women who were willing to postpone antimicrobial therapy by accepting a delayed prescription. Where the GP actually asked patients to postpone treatment, one-third of the women were prepared to do so, ${ }^{1920}$ but this increased to two-thirds when willingness to postpone was assessed by questionnaire. ${ }^{19} 20$

Several studies have compared antimicrobial and nonsteroidal anti-inflammatory drug (NSAID) treatment in terms of safety and effectiveness. Three randomised controlled trials in primary care looked at the time to symptom resolution and found a difference in favour of antimicrobial treatment that ranged from 1 to 3 days. ${ }^{21-23}$ Treatment with antimicrobial drugs also resulted in fewer cases of pyelonephritis compared with NSAID treatment, with risk differences ranging from $2 \%$ to $5 \%$ and with no differences in other adverse events. ${ }^{21-23}$ Treatment duration was 3 days for all interventions in these studies. Although antimicrobial therapy performed better than NSAID therapy, the differences fell within the range that women would consider tolerable if it meant avoiding treatment with antimicrobials. It should be noted that symptom recurrence was more common in the NSAID groups in these studies (risk difference 1\%-5\%), ${ }^{21}{ }^{22}$ with $31 \%-46 \%$ of women who received NSAIDs eventually switching to antimicrobial therapy for their UTI within 4 weeks. ${ }^{21}{ }^{23}$ Nevertheless, NSAIDs can be a viable alternative for many women, resulting in a net decrease in antimicrobial drug use when this approach is followed.

It is increasingly acknowledged that patient preference should be considered when making treatment decisions. However, such an approach is conspicuous by its absence in the treatment of UTI, as illustrated by the growth in antimicrobial drug prescriptions for this indication. This absence is further exacerbated by the fact that it may be neither appropriate nor necessary to prescribe in all situations. Indeed, we showed that women value treatment alternatives to antimicrobial drugs and are even willing to tolerate less optimal therapy to avoid their use. Future studies must now focus on how best to introduce decision making protocols if we are to reduce unnecessary antimicrobial drug prescribing safely and give more insight into which patients are at risk of developing complications when not prescribing antimicrobial drugs.

\section{Twitter Marco H Blanker @Marco_Blanker}

Acknowledgements We thank Dr Robert Sykes (www.doctored.org.uk) for providing editorial assistance.

Contributors HvdW and MHB conceived the idea. All authors worked on designing the experiment. PAB, JHWB, LJFB and JK collected the data. HvdW analysed the data with assistance from DB. HvdW and MHB drafted the manuscript. All authors contributed to the interpretation of results and provided important intellectual contributions to the manuscript. All authors read and approved the final manuscript. HvdW is the guarantor of the work.
Funding The authors have not declared a specific grant for this research from any funding agency in the public, commercial or not-for-profit sectors.

Competing interests None declared.

Patient consent for publication Not required.

Ethics approval The Medical Ethical Committee of the University Medical Center Groningen approved the study (METc 201.722).

Provenance and peer review Not commissioned; externally peer reviewed.

Data availability statement Data are available upon reasonable request. Data collected for this study will be available from the authors upon request.

Supplemental material This content has been supplied by the author(s). It has not been vetted by BMJ Publishing Group Limited (BMJ) and may not have been peer-reviewed. Any opinions or recommendations discussed are solely those of the author(s) and are not endorsed by BMJ. BMJ disclaims all liability and responsibility arising from any reliance placed on the content. Where the content includes any translated material, BMJ does not warrant the accuracy and reliability of the translations (including but not limited to local regulations, clinical guidelines, terminology, drug names and drug dosages), and is not responsible for any error and/or omissions arising from translation and adaptation or otherwise.

Open access This is an open access article distributed in accordance with the Creative Commons Attribution Non Commercial (CC BY-NC 4.0) license, which permits others to distribute, remix, adapt, build upon this work non-commercially, and license their derivative works on different terms, provided the original work is properly cited, appropriate credit is given, any changes made indicated, and the use is non-commercial. See: http://creativecommons.org/licenses/by-nc/4.0/.

\section{ORCID iDs}

Henk van der Worp http://orcid.org/0000-0001-5545-4155

Marco H Blanker http://orcid.org/0000-0002-1086-8730

\section{REFERENCES}

1 Nielen MMJ, Schermer TMJ. Incidentie en prevalentie van gezondheidsproblemen in de Nederlandse huisartsenpraktijk, 2020. Available: https://www.henw.org/artikelen/incidentie-en-prevalentievan-gezondheidsproblemen-de-huisartspraktijk

2 Bouma M, Geerlings SE, Klinkhamer S. the NHG practice guideline 'urinary tract infections'. The Dutch College of General Practitioners, 2020.

3 Laxminarayan R, Duse A, Wattal C, et al. Antibiotic resistance-the need for global solutions. Lancet Infect Dis 2013;13:1057-98.

4 Mulder M, Baan E, Verbon A, et al. Trends of prescribing antimicrobial drugs for urinary tract infections in primary care in the Netherlands: a population-based cohort study. BMJ Open 2019;9:e027221:2018-7221.

5 Netherlands Institute for Health Services Research. Percentage patiënten dat antibioticum krijgt voorgeschreven daalt iets. Available: https://www.nivel.nl/nl/nieuws/percentage-patienten-datantibioticum-krijgt-voorgeschreven-daalt-iets [Accessed 10 Sep 2021].

6 European Centre for Disease Prevention and Control. Rates by country. Available: https://www.ecdc.europa.eu/en/antimicrobialconsumption/database/rates-country [Accessed 10 Sept 2021].

7 Gágyor I, Strube-Plaschke S, Rentzsch K, et al. Management of urinary tract infections: what do doctors recommend and patients do? an observational study in German primary care. BMC Infect Dis 2020;20:813.

8 Brabers AEM, Van Esch TEM, Groenewegen PP, et al. Is there a conflict between general practitioners applying guidelines for antibiotic prescribing and including their patients' preferences? Patient Prefer Adherence 2017;12:9-19.

9 Lancsar E, Louviere J. Conducting discrete choice experiments to inform healthcare decision making. Pharmacoeconomics 2008;26:661-77.

10 de Bekker-Grob EW, Ryan M, Gerard K. Discrete choice experiments in health economics: a review of the literature. Health Econ 2012;21:145-72.

11 Reed Johnson F, Lancsar E, Marshall D, et al. Constructing experimental designs for Discrete-Choice experiments: report of the ISPOR conjoint analysis experimental design good research practices Task force. Value in Health 2013;16:3-13.

12 Traets F, Sanchez DG, Vandebroek M. Generating optimal designs for discrete choice experiments in R: the Idefix package. Journal Of Statistical Software 2019;96. 
13 Hauber AB, González JM, Groothuis-Oudshoorn CGM, et al. Statistical methods for the analysis of discrete choice experiments: a report of the ISPOR conjoint analysis good research practices Task force. Value in Health 2016:19:300-15.

14 Statistics Netherlands. Bevolking; onderwijsniveau; geslacht, leeftijd en migratieachtergrond. Available: https://opendata.cbs.nl/statline/\#/ $\mathrm{CBS} / \mathrm{nl} /$ dataset/82275NED/table?dl=4596F [Accessed 10 Nov 2020].

15 Haugom LEA, Ruths S, Emberland KE, et al. Consultations and antibiotic treatment for urinary tract infections in Norwegian primary care 2006-2015, a registry-based study. BMC Fam Pract 2021;22:127.

16 de Bekker-Grob EW, Donkers B, Jonker MF, et al. Sample size requirements for discrete-choice experiments in healthcare: a practical guide. Patient 2015;8:373-84

17 Leydon GM, Turner S, Smith $\mathrm{H}$, et al. Women's views about management and cause of urinary tract infection: qualitative interview study. BMJ 2010;340:c279.

18 Duane S, Beatty P, Murphy A, et al. Exploring experiences of delayed prescribing and symptomatic treatment for urinary tract infections among general practitioners and patients in ambulatory care: a qualitative study. Antibiotics 2016;5:27.

19 Knottnerus BJ, Geerlings SE, Moll van Charante EP, et al. Women with symptoms of uncomplicated urinary tract infection are often willing to delay antibiotic treatment: a prospective cohort study. BMC Fam Pract 2013;14:2296-14-71.

20 Willems CSJ, van den Broek D'Obrenan J, Numans ME, et al. Cystitis: antibiotic prescribing, consultation, attitudes and opinions. Fam Pract 2014;31:149-55.

21 Gágyor I, Bleidorn J, Kochen MM, et al. Ibuprofen versus fosfomycin for uncomplicated urinary tract infection in women: randomised controlled trial. BMJ2015;351:h6544.

22 Kronenberg A, Bütikofer L, Odutayo $\mathrm{A}$, et al. Symptomatic treatment of uncomplicated lower urinary tract infections in the ambulatory setting: randomised, double blind trial. BMJ 2017;359:j4784.

23 Vik I, Bollestad M, Grude N, et al. Ibuprofen versus pivmecillinam for uncomplicated urinary tract infection in women - a double-blind, randomized non-inferiority trial. PLoS Med 2018;15:e1002569. 